\title{
BIODEGRADATION PROPERTIES OF AZ31 MAGNESIUM ALLOY COATED BY DICALCIUM PHOSPHATE DIHYDRATE
}

\begin{abstract}
Biodegradation properties of magnesium and its alloys that can be used for implants are not satisfactory and cause serious problems. These problems can be solved by biodegradable surface coatings. Evaluation of biodegradation process of Mg-3Al-1Zn alloy surfaces after grinding and grinding followed by potential controlled electrodeposition of dicalcium phosphate dihydrate (DCPD) was investigated by electrochemical impedance spectroscopy measurements in this study. The potentiostatic electrodeposition treatment process was performed in water solution of $\mathrm{Ca}\left(\mathrm{NO}_{3}\right) 2.4 \mathrm{H}_{2} \mathrm{O}, \mathrm{NH}_{4} \mathrm{H}_{2} \mathrm{PO}_{4}$ and $\mathrm{H}_{2} \mathrm{O}_{2}$. The corrosion process on treated and nontreated samples after various exposure times was evaluated in $0.9 \% \mathrm{NaCl}$ solution simulating body fluid environment at $37^{\circ} \mathrm{C}$.
\end{abstract}

Keywords: Magnesium alloy, electrodeposition, calcium phosphate, electrochemical impedance spectroscopy.

\section{Introduction}

Magnesium is an exceptionally lightweight metal. With a density of $1.74 \mathrm{~g} / \mathrm{cm}^{3}$, magnesium is 1.6 and 4.5 times less dense than aluminum and steel, respectively [1 - 3]. The fracture toughness of magnesium is greater than ceramic biomaterials such as hydroxyapatite, while the elastic modulus and compressive yield strength of magnesium are closer to those of natural bone than is the case for other commonly used metallic implants made of stainless steel or titanium [4 - 10]. Moreover, magnesium is essential to human metabolism and is naturally found in bone tissue. It is the fourth most abundant cation in the human body, with an estimated $1 \mathrm{~mol}$ of magnesium stored in the body of a normal $70 \mathrm{~kg}$ adult, with approximately half of the total physiological magnesium stored in bone tissue [11].

The unfortunate complication is that pure magnesium and its alloys can corrode too quickly in the physiological pH (7.4 - 7.6) and high chloride environment of the physiological system, losing mechanical integrity before the tissue has sufficiently healed and producing hydrogen gas in the corrosion process at a rate that is too fast to be dealt with by the host tissue [12]. It is likely that in spite of some early successes with magnesium-based implants [13], the metal was abandoned due to the production of gas during the in vivo corrosion process when stainless steels became available. Several possibilities exist to tailor the corrosion rate of magnesium by using alloying elements and protective coatings, processes that, of course, must lead to a non-toxic, biologically compatible material [4, 12 and 14].
Calcium phosphates have been researched extensively for biomedical applications due to their high biocompatibility and bioactivity [15]. Unfortunately, these ceramic biomaterials do not have the mechanical strength to enable them to succeed in load bearing applications. However, implant materials such as stainless steels and titanium alloys are coated with calcium phosphates [16 - 18].

Compared to conventional preparation methods, such as hot spraying or laser cladding, the structure of $\mathrm{Ca}-\mathrm{P}$ coatings formed in solution is closer to that of the bone minerals [19]. Moreover, the electrodeposition technique could cost-effectively adjust the morphologies and compositions of Ca-P coatings [20].

The aim of this study is to create calcium phosphate coating on the surface of AZ31 magnesium alloy by potential-controlled electrodeposition and to evaluate the corrosion protection influence of this coating during exposure in electrolyte simulating a human body environment.

\section{Experimental material and methods}

Magnesium alloy AZ31 was chosen as the experimental material. It was continually cast at Brandenburgische Universitat in Cottbus, Germany, heat-treated by annealing $\left(420{ }^{\circ} \mathrm{C}, 6\right.$ hours $)$ at TU Clausthal, Germany and its chemical composition was analyzed at the Magnesium innovation centre MagIC GKSS

\footnotetext{
* 1,2Filip Pastorek, ${ }^{1}$ Miroslav Omasta, ${ }^{2}$ Lenka Bukovinova, ${ }^{3}$ Pavel Dolezal, ${ }^{1,2}$ Branislav Hadzima

'Department of Materials Engineering, Faculty of Mechanical Engineering, University of Zilina, Slovakia

${ }^{2}$ Research centre of the University of Zilina, Slovakia

${ }^{3}$ Institute of Material Science and Engineering, Faculty of Mechanical Engineering, Brno University of Technology, Czech Republic

E-mail: filip.pastorek@fstroj.uniza.sk
} 
Chemical composition of AZ31 alloy

Table 1

\begin{tabular}{|c|c|c|c|c|c|c|c|c|}
\hline Component & $\mathrm{Al}$ & $\mathrm{Zn}$ & $\mathrm{Mn}$ & $\mathrm{Si}$ & $\mathrm{Cu}$ & $\mathrm{Ni}$ & $\mathrm{Fe}$ & $\mathrm{Mg}$ \\
\hline wt. $\%$ & 2.96 & 0.828 & 0.433 & 0.004 & 0.004 & $<0.001$ & 0.002 & bal. \\
\hline
\end{tabular}

Geesthacht, Germany. The chemical composition is listed in Table 1.

The microstructure of AZ31 alloy (Fig. 1) was observed by the CARL ZEISS AXIO Imager.A1m light metallographic microscope using AxionVision Rel 4.5 software and AxioCam MRc5 camera in the laboratories of the Department of Materials Engineering, University of Zilina. The microstructure of AZ31 alloy is created by polyedric grains of supersaturated solid solution of aluminum, zinc and other alloying elements in magnesium (solid solution $\delta$ ). The average grain size is $220 \mu \mathrm{m}$.

AZ31 magnesium alloy samples with surface area of $2 \mathrm{~cm}^{2}$ were ground with 500 and 1000 grit $\mathrm{SiC}$ paper to ensure the same surface roughness, then rinsed with demineralized water and ethanol, and dried using a stream of hot air. After described pre-treating the dicalcium phosphate dihydrate (DCPD) was deposed on the samples' surfaces. Treatment electrolyte solution was prepared with $0.1 \mathrm{M} \mathrm{Ca}\left(\mathrm{NO}_{3}\right)_{2} \cdot 4 \mathrm{H}_{2} \mathrm{O}+0.06 \mathrm{M} \mathrm{NH}_{4} \mathrm{H}_{2} \mathrm{PO}_{4}$ $+10 \mathrm{ml}^{-1} \mathrm{H}_{2} \mathrm{O}_{2}$. A classical three-electrode system consisting of counter electrode (platinum electrode), reference electrode (saturated calomel electrode) and working electrode (sample) was used for electrodeposition process. Electrodeposition was performed with constant potential $-1.8 \mathrm{~V}$ vs reference electrode potential for 1 hour at room temperature $22 \pm 2{ }^{\circ} \mathrm{C}$ on a laboratory apparatus VSP (producer BioLogic SAS France).

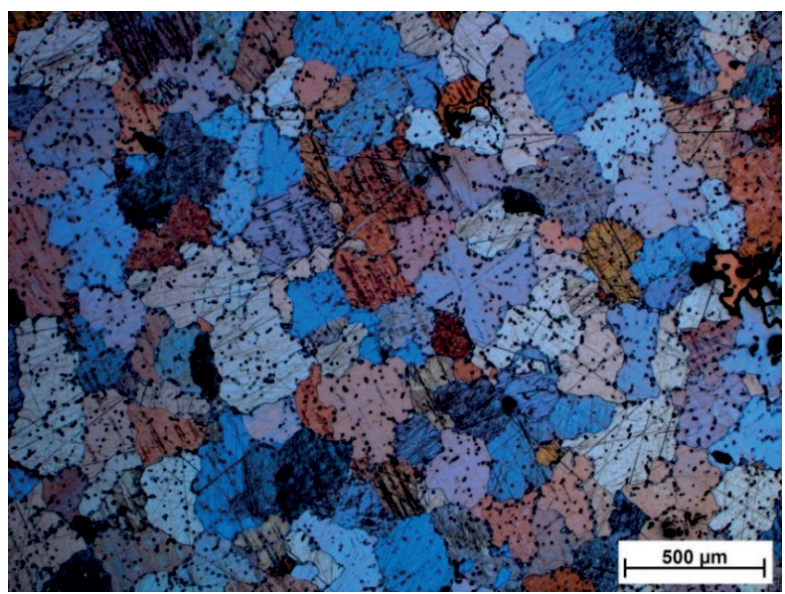

Fig. 1 Microstructure of AZ31 alloy, light microscopy, etch. picric acid + ac. acid + ethanol + water [21]

\section{Results and discussion}

The surface morphology of the treated samples (Fig. 2) was assessed by a stereomicroscope Nikon AZ100 with a digital camera using NIS Elements software. As can be seen, the continuous layer of DCPD covering the entire surface is composed of irregularly branched units that overlap each other.

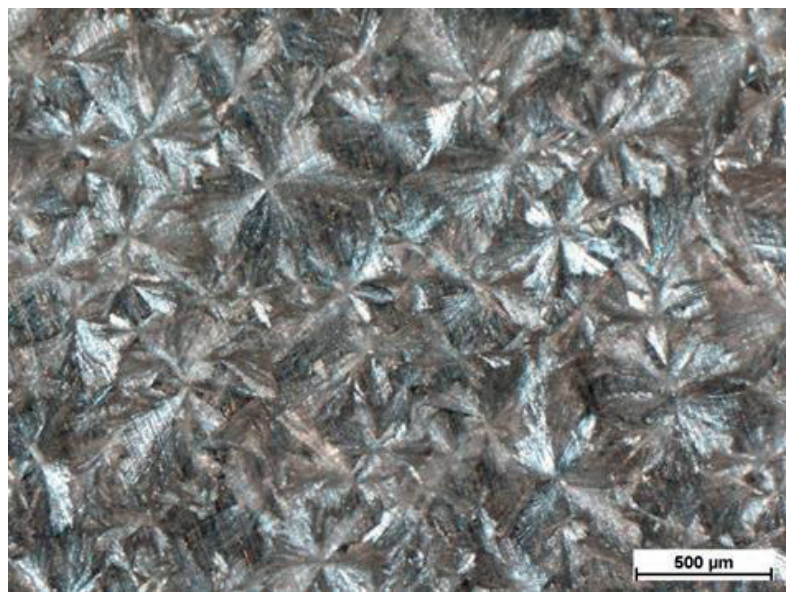

Fig. 2 Morphology of created calcium phosphate, light microscopy

Electrochemical impedance spectroscopy (EIS) was used for the corrosion resistance evaluation of surface layers after exposure times from 5 minutes to 168 hours in $0.9 \% \mathrm{NaCl}$ solution at 37 $\pm 1{ }^{\circ} \mathrm{C}$, which represents human body environment conditions. Corrosion electrochemical characteristics were measured and evaluated by a potentiostat/galvanostat/frequency response analyzer VSP from BioLogic SAS France. EIS measurements were performed at open circuit potential with $\mathrm{AC}$ voltage amplitude of $15 \mathrm{mV}$ in frequency range from $100 \mathrm{kHz}$ to $10 \mathrm{mHz}$.

Results from EIS measurements in the form of impedance and phase Bode plots are shown in Fig. 3 and Fig. 4 for AZ31 samples with ground surface and surface coated by DCPD, respectively. Bode plots were analyzed by software EC-Lab V10.12 using equivalent circuits. Fig. 5 expresses the equivalent circuit used for the analysis of Bode plots with one minimum in phase shift vs $\log f$ interpretation and Fig. 6 the equivalent circuit used for the analysis of Bode plots with two minimums in phase shift vs $\log f$ interpretation [3]. These equivalent circuits use various elements expressing the character of evaluated surface. In our case, $R_{\Omega}$ is resistance of the solution, $R_{p 1}$ and $R_{p 2}$ are polarization resistances of various mechanisms in corrosion model (e.g. charge transfer, film resistance,...), $R_{p}$ is mixed polarization resistance or sum of partial polarization resistances $\left(R_{p 1}+R_{p 2}\right)$ and $C P E_{1}$ and $C P E_{2}$ are constant phase elements of mechanisms corresponding with $R_{p l}$ and $R_{p 2}$, respectively. $C P E_{1}$ in second equivalent circuit is constant phase element of the layer of corrosion products. 


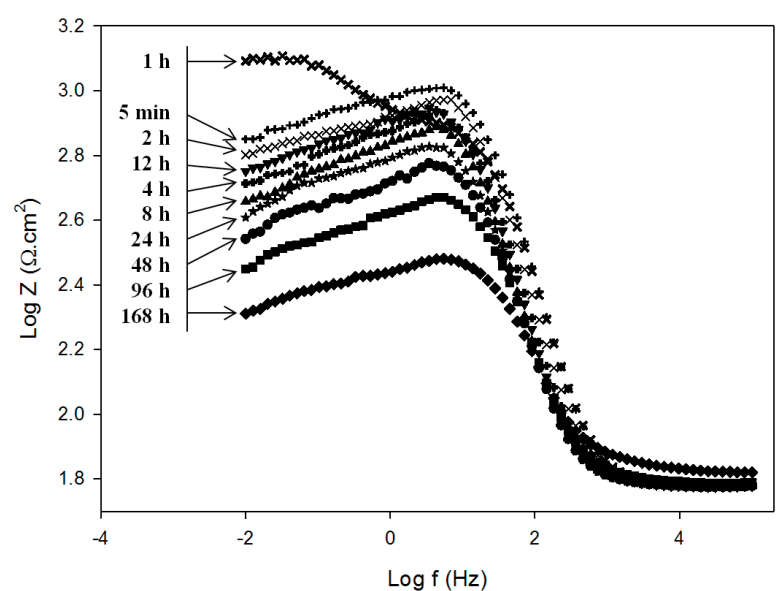

a)

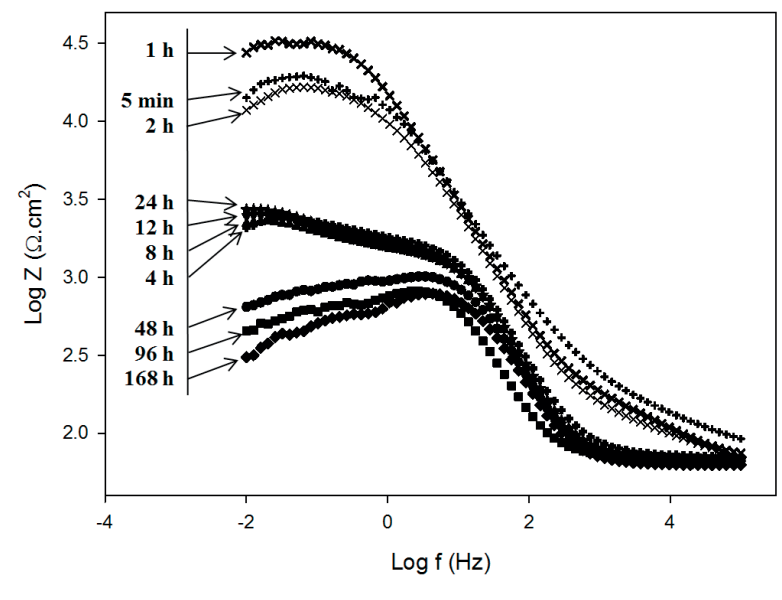

b)

Fig. 3 Impedance Bode plots of AZ31 samples: a) Ground surface, b) Surface with DCPD layer

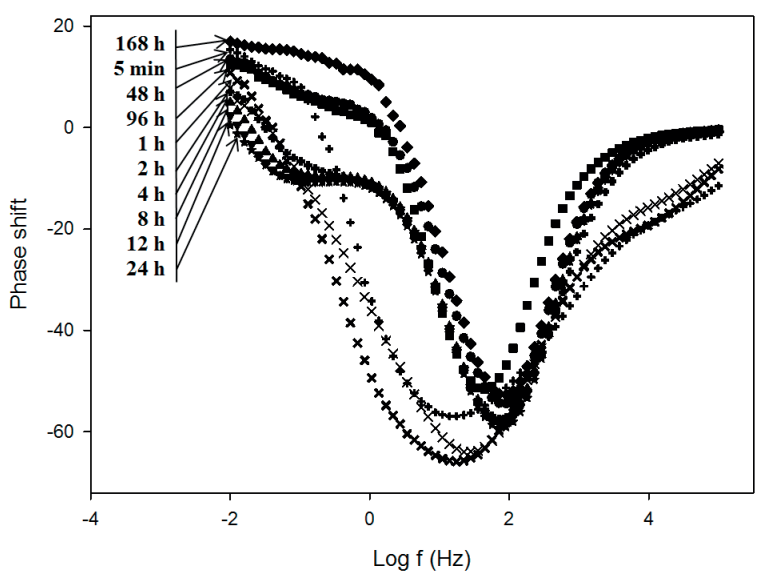

a)

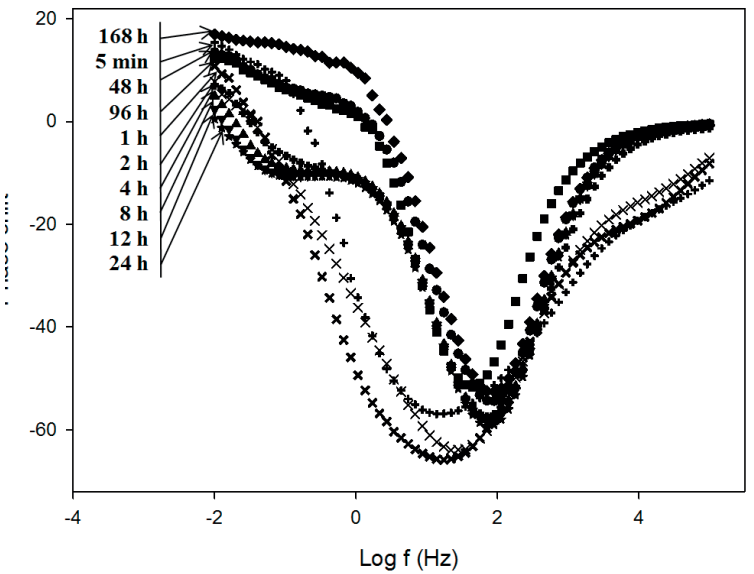

b)

Fig. 4 Phase Bode plots of AZ31 samples: Ground surface, b) Surface with DCPD layer

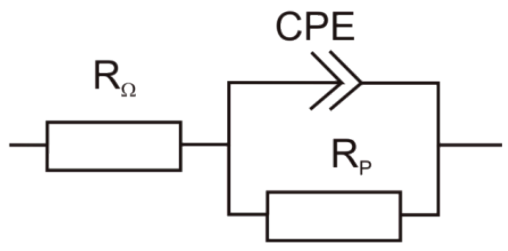

Fig. 5 Equivalent circuit used for the analysis of Bode plots with one minimum in phase shift vs log finterpretation

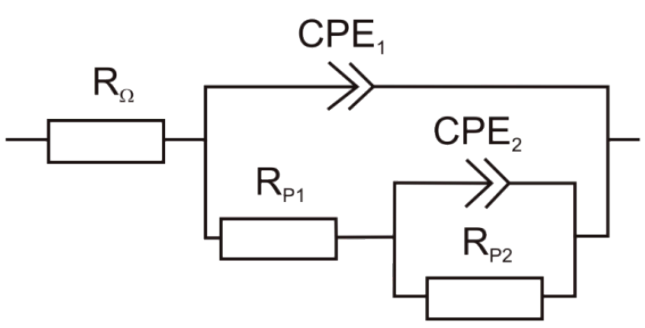

Fig. 6 Equivalent circuit used for the analysis of Bode plots with two minimums in phase shift vs log finterpretation

Based on Bode plots analysis the values of polarization resistance $R_{p}$ were obtained. This electrochemical characteristic represents the corrosion resistance of the surface layer (or layers). The values of polarization resistances and other electrochemical characteristics gained after various exposure times on AZ31 magnesium alloy samples without and with DCPD coating are listed in Table 2. 
Polarization resistance values of the ground AZ31 samples and ground AZ31 samples with DCPD surface layer after various exposure times $(0.9 \% \mathrm{NaCl})$

Table 2

\begin{tabular}{|c|c|c|c|c|c|c|c|c|c|c|}
\hline & $5 \min$ & $1 \mathrm{~h}$ & $2 \mathrm{~h}$ & $4 \mathrm{~h}$ & $8 \mathrm{~h}$ & $12 \mathrm{~h}$ & $24 \mathrm{~h}$ & $48 \mathrm{~h}$ & $96 \mathrm{~h}$ & $168 \mathrm{~h}$ \\
\hline $\begin{array}{c}R_{p}\left(\Omega \cdot \mathrm{cm}^{2}\right) \\
\text { ground }\end{array}$ & 1059 & 1239 & 985 & 825 & 729 & 836 & 625 & 539 & 410 & 241 \\
\hline $\begin{array}{c}R_{p}\left(\Omega \cdot \mathrm{cm}^{2}\right) \\
\text { ground + DCPD }\end{array}$ & 19047 & 34972 & 16868 & 2421 & 2236 & 2664 & 2729 & 953 & 772 & 730 \\
\hline
\end{tabular}

A formation of the surface layer of corrosion products based on magnesium oxide $(\mathrm{MgO})$ and hydroxide $\left(\mathrm{Mg}(\mathrm{OH})_{2}\right)$ was observed in a short time after the immersion of the ground AZ31 sample in $0.9 \% \mathrm{NaCl}$ at $37{ }^{\circ} \mathrm{C}$. This formation resulted in the increase of polarization resistance $R_{p}$ values which is terminated after 1 hour of exposure when the maximum value of $R_{p}$ (1239 $\Omega . \mathrm{cm}^{2}$ ) was reached. By increase of exposure time the gradual decrease of $R_{p}$ values is observed up to a minimum $241 \Omega . \mathrm{cm}^{2}$ measured after 168 hours of exposure. The decrease of $R_{p}$ values can be explained by the degradation of the surface layer formed of corrosion products and by the subsequent local corrosion attack realized by aggressive components of electrolyte.

AZ31 samples with DCPD surface layer showed substantial increase of polarization resistance $R_{p}$ values after various exposure times in corrosive environment at $37^{\circ} \mathrm{C}$ compared to ground AZ31 samples. The value of $R_{p}\left(19047 \Omega . \mathrm{cm}^{2}\right)$ reached on the surface with DCPD layer after 5 minutes of exposure was 19 . fold higher compared to ground samples at the same exposure. Maximal polarization resistance value $R_{p}\left(34972 \Omega . \mathrm{cm}^{2}\right)$ reached after 1 hour of exposure represented more than 29 times higher value compared to the maximal value of $R_{p}$ reached on ground samples. Corrosion process of the samples with DCPD surface layer is different from the corrosion process of ground samples. At the moment of the samples immersion a reaction of DCPD with the corrosive medium $\left(0.9 \% \mathrm{NaCl}, 37^{\circ} \mathrm{C}\right)$ and the formation of corrosion products in places with insufficient DCPD coverage occurred. These two processes resulted in filling imperfections in the DCPD layer thus increasing the polarization resistance $R_{p}$. After 2 hours of exposure there was a decrease in $R_{p}$ values (to $16868 \Omega . \mathrm{cm}^{2}$ ) caused by a gradual degradation of the surface resulting in local increase of corrosion activity in the weakest DCPD locations. This gradual decrease of $R_{p}$ values caused by ongoing DCPD dissolution and more intensive corrosion continued till the end of the immersion test after 168 hours when the minimal value of $R_{p}$ was reached (730 $\left.\Omega . \mathrm{cm}^{2}\right)$. Despite of significant loss of DCPD corrosion protection after longer exposure times, the polarization resistance values of the surface with DCPD layer are significantly higher after all exposure times compared to ground surface.

\section{Conclusions}

On the basis of performed experiments, analysis of the results and their interpretations, we came to the following conclusions:

1. Thin calcium phosphate dihydrate (DCPD) coating prepared by potential-controlled electrodeposition process under specified conditions forms the continuous layer composed of irregularly branched flake-like formations of a different size covering the entire surface.

2. The polarization resistance $\left(R_{p}\right)$ value of $\mathrm{AZ} 31$ samples with DCPD coating $\left(19047 \Omega . \mathrm{cm}^{2}\right)$ reached after first 5 minutes of exposure in corrosive medium achieves 19-fold higher value compared to that of ground samples $\left(1059 \Omega . \mathrm{cm}^{2}\right)$ after the same exposure time which represents a relevant improvement of surface layer corrosion protection.

3. Maximum value of $R_{p}$ reached on samples with DCPD coating after 1 hour of exposure $\left(34972 \Omega . \mathrm{cm}^{2}\right)$ is 29 times higher than the maximum $R_{p}$ value of the samples with ground surface (1239 $\left.\Omega . \mathrm{cm}^{2}\right)$ recorded also after this exposure time.

4. Prepared DCPD coating provides significant corrosion protection in $0.9 \% \mathrm{NaCl}$ solution at $37{ }^{\circ} \mathrm{C}$ for 4 hours of exposure. Consequently, there is a gradual degradation of the coating and local corrosion processes as evidenced by decrease in polarization resistance values.

5. This surface layer provides higher corrosion resistance of the AZ31 surface layer at all of the selected exposure times when there is still a 3 -fold higher value of $R_{p}$ measured on samples with DCPD coating compared to ground samples after maximal exposure time 168 hours.

\section{Acknowledgements}

The research is supported by European regional development fund and Slovak state budget by the project: Research centre of the University of Zilina, ITMS 26220220183 and Unique equipment for evaluation of tribological properties of machines parts surfaces, ITMS 26220220048. Authors are grateful for the support of experimental works by project VEGA No. 1/0831/13. 


\section{References}

[1] Degarmo, P. E.: Materials and Processes in Manufacturing, $5^{\text {th }}$ ed., New York: Collin Macmillan, 1979.

[2] HLAVACOVA, I., PALCEK, P., CHALUPOVA, M., DRESSLEROVA, Z.: Manufacturing Technology, 13, 2013, 313-319.

[3] JANECEK, M., KRAL, R., DOBRON, P., CHMELIK, F., SUPIK, V., HOLLANDER, F.: Mater. Sci. Eng.: A 462, 2007, $311-315$.

[4] PASTOREK, F., HADZIMA, B.: Mater. Eng. - Mater. inz. 20, 2013, 54-63.

[5] SARIS, N. E. L.: Clin. Chim. Acta 294, 2000, 1-26.

[6] OKUMA, T.: Nutrition 17, 2001, 679-680.

[7] VORMANN, J.: Mol. Aspects Med. 24, 2003, 27-37.

[8] CZAN, A., SAJGALIK, M., HOLUBJAK, J., KOURIL, K.: Manufacturing Technology 13, 2013, 428-431.

[9] BRONCEK, J., DZIMKO, M., HADZIMA, B., TAKEICHI, Y.: Acta Metallurgica Slovaca 20, 2014, 97-104.

[10] HALAMOVA, M., LIPTAKOVA, T., ALASKARI, A., BOLZONI, F.: Communications - Scientific Letters of the University of Zilina, vol. 16, 2014, 78-83.

[11] HARTWIG, A.: Mutat Res/Fund Mol Mech Mutagen 475, 2001, 113-121.

[12] WITTE, F., KAESE, V., HAFERKAMP, H., SWITZER, E., MEYER-LINDENBERG, A., WIRTH, C. J.: Biomaterials 26, 2005, 3557-3563.

[13] MCBRIDE, E. D.: J Am Med Assoc 111, 1938, 2464-2467.

[14] HADZIMA, B., BUKOVINA, M., DOLEZAL, P.: Mater. Eng. - Mater. inz. 17(4), 2010, 14-19.

[15] BEST, S. M., PORTER, A. E., THIAN, E. S., JUANG, J.: J. Eur. Ceram. Soc. 28, 2008, 1319-1327.

[16] YEN, S. K., KUA, M. C.: Mater. Sci. Eng. C 20, 2002, 153-160.

[17] LIU, D.-M., YANG, Q., TROCZYNSKI, T.: Biomaterials 23, 2002, 691-698.

[18] KANNAN, M. B., WALLIPA, O.: Mater. Sci. Eng. C 33, 2013, 675-679.

[19] ZHANG, J. M., LIN, C. J., FENG, Z. D., TIAN, Z. W.: J Electroanal Chem 452, 1998, 235-40.

[20] SONG, Y., ZHANG, S., LI, J., ZHAO, Ch., ZHANG, X.: Acta Biomaterialia 6, 2010, 1736-1742.

[21] NOVY, F., JANECEK, M., SKORIK, V., MULLER, J., WAGNER, L.: Int. J. Mater. Res. 100, 2009, $288-291$. 